\title{
Quantification of Niacin and Its Metabolite Nicotinuric Acid in Human Plasma by LC-MS/MS: Application to a Clinical Trial of a Fixed Dose Combination Tablet of Niacin Extended-Release/Simvastatin $(500 \mathrm{mg} / 10 \mathrm{mg})$ in Healthy Chinese Volunteers
}

\author{
Pingping Zhang, ${ }^{1}$ Yantong Sun, ${ }^{2}$ Guobing Shi, ${ }^{1}$ Yin Sui, ${ }^{1}$ \\ Qiuying $\mathbf{L i},{ }^{1}$ Yunbiao Tang, ${ }^{1}$ and Jingkai $\mathbf{G u}^{2}$ \\ ${ }^{1}$ Department of Pharmacy, General Hospital of Shenyang Military Area Command, No. 83, Wenhua Road, \\ Shenhe District, Shenyang 110840, China \\ ${ }^{2}$ Research Center for Drug Metabolism, School of Life Sciences, Jilin University, Changchun 130012, China \\ Correspondence should be addressed to Yunbiao Tang; tangyb99@163.com and Jingkai Gu; gujk@mail.jlu.edu.cn
}

Received 4 April 2015; Revised 1 July 2015; Accepted 12 July 2015

Academic Editor: Jan Åke Jönsson

Copyright (C) 2015 Pingping Zhang et al. This is an open access article distributed under the Creative Commons Attribution License, which permits unrestricted use, distribution, and reproduction in any medium, provided the original work is properly cited.

\begin{abstract}
Our paper aimed to develop rapid, sensitive, and specific LC-MS/MS method for the quantification of niacin (NA) and its metabolite nicotinuric acid (NUA) in human plasma. Following protein precipitation with acetonitrile, the NA, NUA, and internal standard (5fluorouracil) were separated on a Zorbax $300 \mathrm{SB}-\mathrm{C}_{8}$ column $(250 \mathrm{~mm} \times 4.6 \mathrm{~mm}, 5 \mu \mathrm{m})$ with a mobile phase consisting of methanol$2 \mathrm{mM}$ ammonium acetate $(3: 97, \mathrm{v} / \mathrm{v}$ ) at a flow rate of $1 \mathrm{~mL} / \mathrm{min}$ (split 1:1). A tandem mass spectrometer equipped with electrospray ionization source was used as the detector and operated in negative ion mode. The linear concentration ranges of the calibration curves were $5-800 \mathrm{ng} / \mathrm{mL}$ for NA and NUA. The intra-assay RSD for quality control (QC) samples were from $5.0 \%$ to $8.7 \%$ for NA, and $5.5 \%$ to $7.6 \%$ for NUA. The interassay RSD for QC samples were from $2.8 \%$ to $9.4 \%$ for NA, and $3.7 \%$ to $5.8 \%$ for NUA. The relative errors for QC samples were from $-2.2 \%$ to $2.3 \%$ for NA, and $-0.6 \%$ to $3.2 \%$ for NUA. The method was successfully applied to the investigation of the pharmacokinetic profiles of NA, NUA in human after single dose administration of Niacin extendedrelease/Simvastatin tablet $(500 \mathrm{mg} / 10 \mathrm{mg})$.
\end{abstract}

\section{Introduction}

Atherogenic dyslipidemia is highly prevalent, especially in patients with insulin resistance and diabetes mellitus. Atherogenic dyslipidemia increases the risk for coronary heart disease and peripheral vascular disease and remains a serious public health problem [1]. Niacin (nicotinic acid, 3-pyridinecarboxylic acid) (NA) is a water soluble vitamin and belongs to the vitamin $\mathrm{B}$ complex [2]. It possesses the ability to decrease low density lipoprotein (LDL) cholesterol level and to increase high density lipoprotein (HDL) cholesterol level which led to its clinical use in the treatment of dyslipidemia and prevention of atherosclerosis [3]. Simvastatin (SV) belonging to the class of pharmaceuticals called statins is a specific and nonreversible competitive inhibitor of HMGCoA reductase, which is used for lowering cholesterol in the patients with hypercholesterolemia and for preventing cardiovascular disease $[4,5]$. It was found that a statin combined with NA can be an attractive option because both have excellent records of improving cardiovascular outcomes and can effectively correct all abnormalities of atherogenic dyslipidemia in patients especially those with diabetes [6]. According to the US Food and Drug Administration (FDA) guidelines, a fixed dose combination of NA and SV for use in patients with complex lipid abnormalities has been approved in 2008 [4]. It may lead to the attainment of 
lipid regulation goals when monotherapy with SV or NA is considered inadequate. Furthermore, the combination of two lipid-lowering agents in one formulation may potentially improve patient compliance. A product containing extendedrelease NA (dose range from 125 to $1000 \mathrm{mg}$ per tablet) and SV (dose range from 5 to $40 \mathrm{mg}$ per tablet) obtained from literature was under extensive investigation and conclusions were drown that SV plus NA regimen was effective, safe, and well tolerated in patients with or without diabetes mellitus [4, 5, 7-9]. NA was rapidly metabolized in vivo to two main metabolites through two pathways: the first is the metabolic route to nicotinuric acid (NUA) and the second is that to Niacin amide (NAM). NAM is further transformed to nicotinamide, nicotinamide- $\mathrm{N}$-oxide, and two pyridone derivatives [10]. The first pathway was thought to be the mechanism responsible for the flushing side effect and hepatotoxicity of NA in human. Moreover, the concentration of NUA was higher than NAM; therefore NUA was selected as an estimation goal [10-12].

Various methods are available for determination of NA alone or NA along with its metabolites in biological fluids, like determination of NA and its metabolites by LC-MS/MS following deproteinization with acetonitrile in rat or human $[3,12-14]$ or with methanol in human or dog $[5,15]$, liquidliquid extraction with ethyl acetate in human $[10,16,17]$, and also solid phase extraction in human [2]. And also there are some investigations about NA combined with statins drug formulations in animal or humans $[5,11,16,17]$. Based on literature survey, we developed a specific LC-MS/MS method for the quantification simultaneously of NA and NUA in human plasma after single dose oral administration of a pharmaceutical formulation containing Simvastatin $10 \mathrm{mg}$ and Niacin $500 \mathrm{mg}$ to healthy Chinese volunteers. By doing this, we hope this study can be of help in substantiating the clinical use of Niacin extended-release/Simvastatin tablet in the treatment of human atherogenic dyslipidemia.

\section{Experimental}

2.1. Chemicals and Standards. NA, NUA, and 5-FU were purchased from National Institute for the Control of Pharmaceutical and Biological Products (Beijing, China). The purities of these compounds were found higher than $98 \%$. Methanol and acetonitrile of HPLC grade were purchased from Fischer Scientific (Fair Lawn, NJ, USA). All other chemicals and solvents were of analytical grade. Milli-Q water used throughout the study was obtained from a Millipore system. Drug-free human plasma was provided by the General Hospital of Shenyang Military Area Command.

\subsection{Instruments}

2.2.1. Mass Spectrometry. The mass spectrometer was API 4000 triple quadrupole system equipped with a TurbolonSpray ESI interface operated in negative multiple reaction monitoring (MRM) mode to monitor the transitions $\mathrm{m} / \mathrm{z}$ $122.0 \rightarrow m / z 78.0, m / z 178.7 \rightarrow m / z 78.0$, and $m / z 128.9 \rightarrow m / z$ 42.1 for NA, NUA, and 5-FU, respectively. The optimized value of declustering potential (DP) and collision energy (CE) were $-30 \mathrm{~V}$ and $-17 \mathrm{eV}$ for $\mathrm{NA},-40 \mathrm{~V}$ and $-25 \mathrm{eV}$ for NUA, $-48 \mathrm{~V}$ and $-26 \mathrm{eV}$ for 5 -FU. Data acquisition was carried out with Analyst 1.5.1 software (AB MDS Sciex).

2.2.2. Liquid Chromatography. Agilent 1100 system (Palo Alto, CA, USA) was used for solvent and sample delivery. The chromatographic separation for two analytes and IS was achieved by using a Zorbax $300 \mathrm{SB}-\mathrm{C}_{8}$ column $(250 \mathrm{~mm} \times$ $4.6 \mathrm{~mm}, 5 \mu \mathrm{m}$; Agilent, USA) protected by $\mathrm{C}_{8}$ guard column $(4.0 \times 3.0 \mathrm{~mm}, 5 \mu \mathrm{m}$; Phenomenex, Torrance, CA, USA). The mobile phase was comprised of methanol-2 $\mathrm{mM}$ ammonium acetate $(3: 97, \mathrm{v} / \mathrm{v})$ at a flow rate of $1 \mathrm{~mL} / \mathrm{min}$ (split $1: 1$ ). The total LC analysis time per injection was $4.5 \mathrm{~min}$ with isocratic elution. An injection volume of $40 \mu \mathrm{L}$ was used for all samples.

2.3. Preparation of Standard and Quality Control Samples. Two separate stock solutions of the analytes were prepared at $1 \mathrm{mg} / \mathrm{mL}$ in methanol-water $(50: 50, \mathrm{v} / \mathrm{v})$ and stored at $-20^{\circ} \mathrm{C}$. A series of standard working solutions for NA and NUA were prepared by diluting stock solution with methanolwater $(50: 50, \mathrm{v} / \mathrm{v})$. The 5 -FU solution was brought to a final concentration of $1000 \mathrm{ng} / \mathrm{mL}$ in acetonitrile from $1 \mathrm{mg} / \mathrm{mL}$ in acetonitrile. All working solutions were stored at $4^{\circ} \mathrm{C}$ and brought to room temperature before use. Calibration standards and quality control samples were prepared by spiking $50 \mu \mathrm{L}$ of the working solutions and $50 \mu \mathrm{L}$ of IS into $100 \mu \mathrm{L}$ of drug-free human plasma. Matrix-matched NA and NUA calibration standards were prepared in plasma at concentrations of $5,10,20,60,200,600$, and $800 \mathrm{ng} / \mathrm{mL}$, respectively. Similarly, NA and NUA quality control (QC) samples were prepared separately in plasma to give concentrations of 10,60 , and $600 \mathrm{ng} / \mathrm{mL}$.

2.4. Sample Preparation. Extraction of NA and NUA was carried out by protein precipitation. First, $50 \mu \mathrm{L}$ of the IS working solution $(1000 \mathrm{ng} / \mathrm{mL} 5-\mathrm{FU})$ and $50 \mu \mathrm{L}$ of water were added to a $100 \mu \mathrm{L}$ aliquot of human plasma. The sample mixture was then deproteinized with $250 \mu \mathrm{L}$ of acetonitrile, and the precipitate was removed by centrifugation at $15000 \mathrm{rpm}$ for $10 \mathrm{~min}$. The supernatant was transferred to another tube and evaporated under a gentle stream of nitrogen at $40^{\circ} \mathrm{C}$ until it is dry. The residue was reconstituted in $150 \mu \mathrm{L}$ mobile phase and vortex-mixed for $30 \mathrm{sec}$. An aliquot of $40 \mu \mathrm{L}$ of the solution was injected into the LC-MS/MS system for analysis.

2.5. Method Validation. Measurements for each analyte in the biological matrix should be validated according to relevant guidelines [18, 19]. Method development and validation included (1) selectivity; (2) accuracy and precision; (3) recovery and matrix effect; (4) the calibration curve; (5) lower limit of quantification; (6) dilution integrity; and (7) stability of analytes in spiked samples.

Selectivity is performed by using blank samples from at least six sources. Peak areas of endogenous compounds coeluting with the analytes should be less than $20 \%$ of the peak area of the LLOQ standard. 
TABLE 1: Precision and accuracy for the analysis of NA and NUA in quality control (QC) samples ( $n=3$ days, 6 replicates per day) in human plasma.

\begin{tabular}{|c|c|c|c|c|c|}
\hline & \multicolumn{2}{|c|}{ Concentration $(\mathrm{ng} / \mathrm{mL})$} & \multicolumn{2}{|c|}{ RSD (\%) } & \multirow{2}{*}{$\begin{array}{l}\text { Relative } \\
\text { error (\%) }\end{array}$} \\
\hline & Added & Found & Intraday & Interday & \\
\hline \multirow{3}{*}{ NA } & 10.0 & 9.72 & 6.4 & 2.8 & -2.8 \\
\hline & 60.0 & 61.4 & 8.7 & 9.4 & 2.3 \\
\hline & 600.0 & 587.3 & 5.0 & 7.4 & -2.2 \\
\hline \multirow{3}{*}{ NUA } & 10.0 & 10.3 & 7.6 & 5.8 & 3.2 \\
\hline & 60.0 & 58.2 & 5.5 & 5.1 & -2.9 \\
\hline & 600.0 & 596.0 & 5.7 & 3.7 & -0.6 \\
\hline
\end{tabular}

The lower limit of quantification (LLOQ) is considered being the lowest calibration standard and established using at least five samples. The calibration curves were defined in three separate runs on the basis of duplicate assays of the spiked plasma samples, and, on the same day, QC samples from three concentrations (Table 1) were determined in replicates $(n=6)$ to calculate the method's accuracy and precision. Calibration curves were constructed using a $1 / x^{2}$ weighting linear regression of the peak-area ratios of the analyte to the IS versus the plasma concentration of the analyte.

Extraction recovery was measured at three levels by comparing the response of the analyte spiked before and after sample preparation. Matrix effects were assessed using a method similar to that reported by Matuszewski et al. (see below) [20].

Dilution integrity was evaluated by spiking the plasma with an analyte concentration above ULOQ and diluting this sample with blank plasma when processing. We investigated three concentrations by dilution of 20 times of QC samples.

Stability studies of NA and NUA should investigate the different storage conditions over time periods that equal or exceed those applied to the actual study samples. The following stability tests were evaluated: (1) stability of the stock solutions of the analytes; (2) freeze and thaw stability of the analytes in the plasma from $-20^{\circ} \mathrm{C}$ to room temperature for three cycles; (3) short-term stability of the analytes in plasma at room temperature before extraction for $3 \mathrm{~h}$ and the ready-to-inject samples (after extraction, in the mobile phase) to the autosampler rack for $4 \mathrm{~h}$; and (4) long-term stability of the analytes in matrix stored at $-20^{\circ} \mathrm{C}$ for two months. All stability tests samples at three concentration levels $(10,60$, and $600 \mathrm{ng} / \mathrm{mL}$ ) were analyzed in triplicate and the deviations were determined in relation to freshly prepared samples.

2.6. Application of the Method. The validated method was applied to the quantification of NA and its metabolite NUA in human plasma obtained from a clinical trial. It was in accordance with the Helsinki Declaration of 1975 (revised in 2008) [21] and approved by the institutional ethics committee.

Before conducting the study all subjects provided written informed consent to participate. The study was designed as randomized, open-label, crossover, and single dose periods with a 7-day washout between each treatment. A total of 12 healthy Chinese volunteers (6 males and 6 females) aged 20 to 35 years with a body mass index between 19 and $24 \mathrm{~kg} / \mathrm{m}^{2}$ were recruited. Subjects were randomized into three groups ( 2 males and 2 females for each treatment). They were orally dosed with Niacin extended-release/Simvastatin 1, 2, and 3 tablets once daily, separately. The venous blood samples were collected at time intervals $(0,0.33,0.66,1.0,1.5,2.0,2.5,3.0$, $3.5,4.0,5.0,6.0,8.0,12$, and $24 \mathrm{~h}$ ) in separate vacutainers during the treatment. All blood samples were centrifuged at $3000 \times \mathrm{g}$ for $10 \mathrm{~min}$ and the plasma was separated and kept frozen at $-20^{\circ} \mathrm{C}$ until analysis.

2.7. Data Analysis. The pharmacokinetic parameters were calculated with data analysis system (DAS) program (version 2.0, Mathematical Pharmacology Professional Committee, Shanghai, China). The maximum plasma concentration $\left(C_{\max }\right)$ and the corresponding time $\left(T_{\max }\right)$ were obtained from observed data. The terminal elimination rate constant $\left(K_{e}\right)$ was estimated with least-squares regression of values in the terminal log-linear region of plasma concentrationtime curves, and the terminal elimination half-life $\left(t_{1 / 2}\right)$ was calculated to be $0.693 / K_{e}$. The area under the curve from time zero to the last sampling time $\left(\mathrm{AUC}_{0-t}\right)$ was determined using the linear trapezoidal rule.

Statistical analysis of pharmacokinetic parameters was performed using SAS version 9.1 (SAS Institute Inc., Cary, North Carolina, USA). A $P$ value of $<0.05$ was considered statistically significant.

\section{Results and Discussion}

3.1. LC-MS/MS Optimization. We used ESI-MS/MS to analyze the compounds. To quantify the analytes using the MRM mode, the full scan and product ion spectra of the analytes and IS were investigated. Owing to the similar functional group pyridine ring and carboxyl group of NA and NUA, it makes them give excellent sensitivity in the negative ESI mode. The deprotonated peak was the predominant form of the molecular ion for NA at $\mathrm{m} / z 122.0$ and NUA at $\mathrm{m} / z$ 178.7. Because of the similar pyridine parent ring, the dominant fragments observed for NA and NUA were both at $\mathrm{m} / z 78$ (Figure 1). The fragment ion $\mathrm{m} / z$ 78, formed by breaking the single carbon-carbon bond between the pyridine ring $\mathrm{C}-2$ site and side chain carbonyl group, was present in the greatest abundance and hence was selected as the product ion for quantitation. Figure 1 displays product ion spectra of the deprotonated molecules of NA, NUA, and their corresponding IS.

In order to optimize the LC system for the detection of NA and NUA, chromatographic separation was tested on several $\mathrm{C}_{18}$ and $\mathrm{C}_{8}$ columns to achieve the best efficiency and peak shape: Phenomenex Gemini $(150 \mathrm{~mm} \times 2.0 \mathrm{~mm}$, $5 \mu \mathrm{m})$, Capcell Pak MG $(150 \mathrm{~mm} \times 2.0 \mathrm{~mm}, 5 \mu \mathrm{m})$, and Discovery $(50 \mathrm{~mm} \times 2.1 \mathrm{~mm}, 5 \mu \mathrm{m})$, while the asymmetrical peak was acquired on the Zorbax $300 \mathrm{SB}-\mathrm{C}_{8}$ column $(250 \mathrm{~mm}$ $\times 4.6 \mathrm{~mm}, 5 \mu \mathrm{m}$; Agilent, USA) for NA and NUA because of good peak shape and satisfactory recovery. Different mobile phases were evaluated to improve LC separation and enhance 


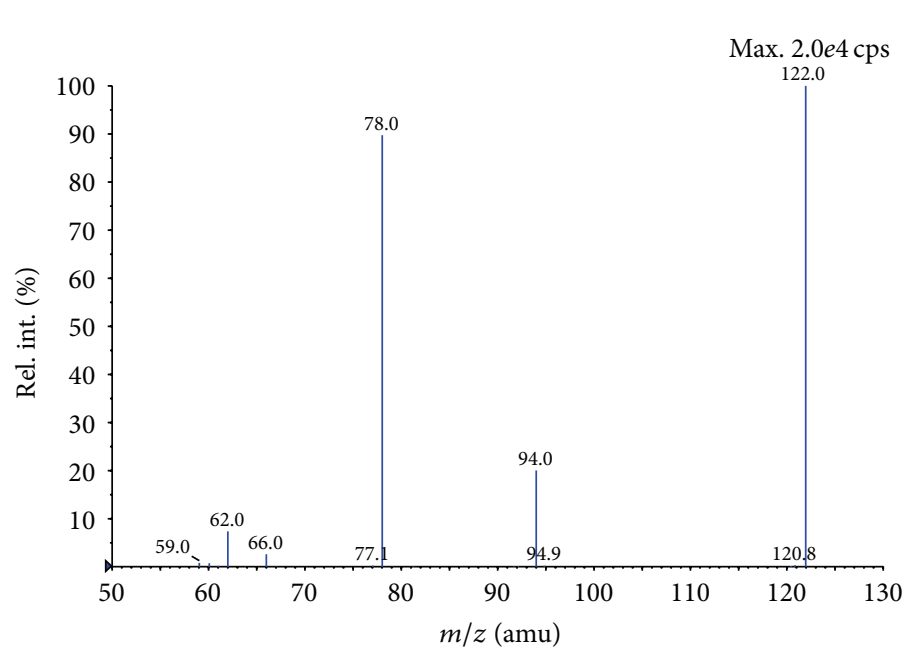

(a)

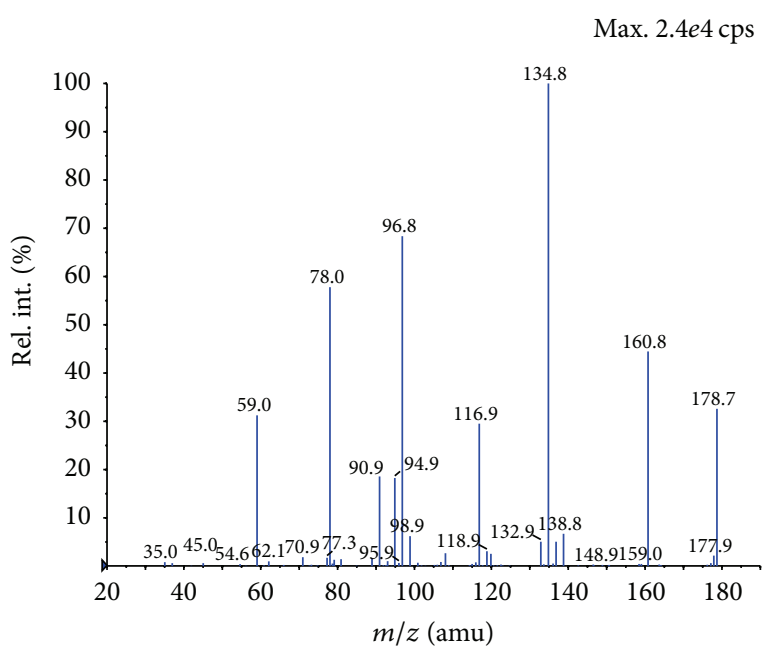

(b)

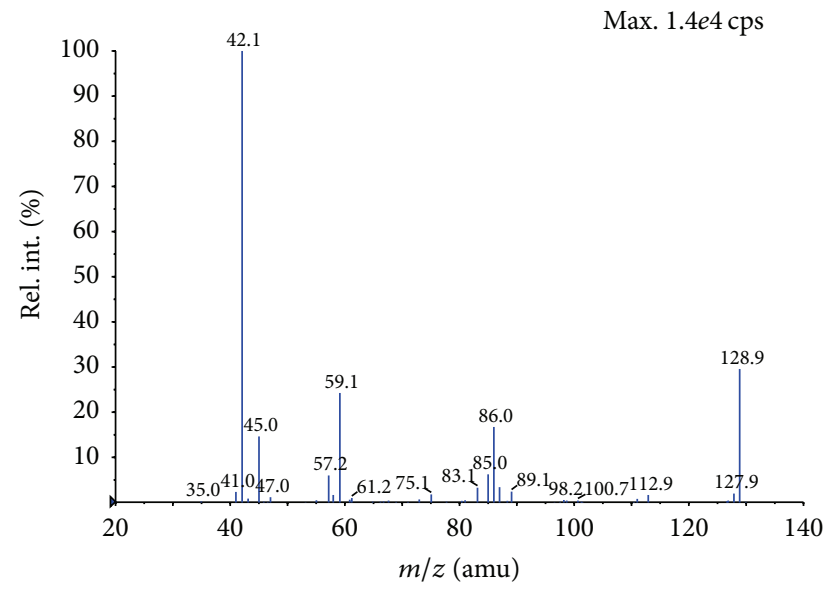

(c)

FIGURE 1: Product ion mass spectra of the deprotonated molecules of NA (a), NUA (b), and 5-FU (c).

MS sensitivity. Methanol was selected as the organic modifier because its ability to ionize NA and NUA was superior to that of acetonitrile. Moreover, the addition of ammonium acetate $(2 \mathrm{mM})$ in the mobile phase greatly increased signal intensity for NA and NUA. Thus, an isocratic system with a mobile phase consisting of methanol and $2 \mathrm{mM}$ ammonium acetate $(3: 97, \mathrm{v} / \mathrm{v})$ was optimal for NA and NUA with respect to peak shape and mass spectral response. Under these chromatographic conditions, the retention time for NA and NUA was approximately $4.5 \mathrm{~min}$.

3.2. Internal Standard Selection. We have chosen 5-FU as an internal standard. Although a stable isotope-labeled compound would be an ideal IS for quantitation in complex matrices in LC-MS/MS analysis, it is not readily available in most laboratories. Hence, structural analogues were screened to find suitable compound for use as IS. 5-FU was finally selected as the IS for the determination of NA and NUA.
3.3. Optimization of Sample Preparation. Prior to loading the sample for LC injection, the coextracted proteins should be removed from the prepared solution. Different extraction procedures like protein precipitation (PPT), liquid-liquid extraction (LLE), and solid phase extraction (SPE) were tested. The largely polar character of NA and NUA makes it difficult to extract from plasma with organic solvents. In this study, NA and NUA were prepared by plasma protein precipitation. Moreover, when acetonitrile was chosen for protein precipitation, the extraction recovery was higher when methanol was used. A reconstitution procedure for the dried extract employed that optimized recovery of all analytes while at the same time sufficiently reduced the presence of endogenous matrices.

\subsection{Method Validation}

3.4.1. Assay Specificity. Method specificity was demonstrated by comparing the MRM chromatograms of blank samples 

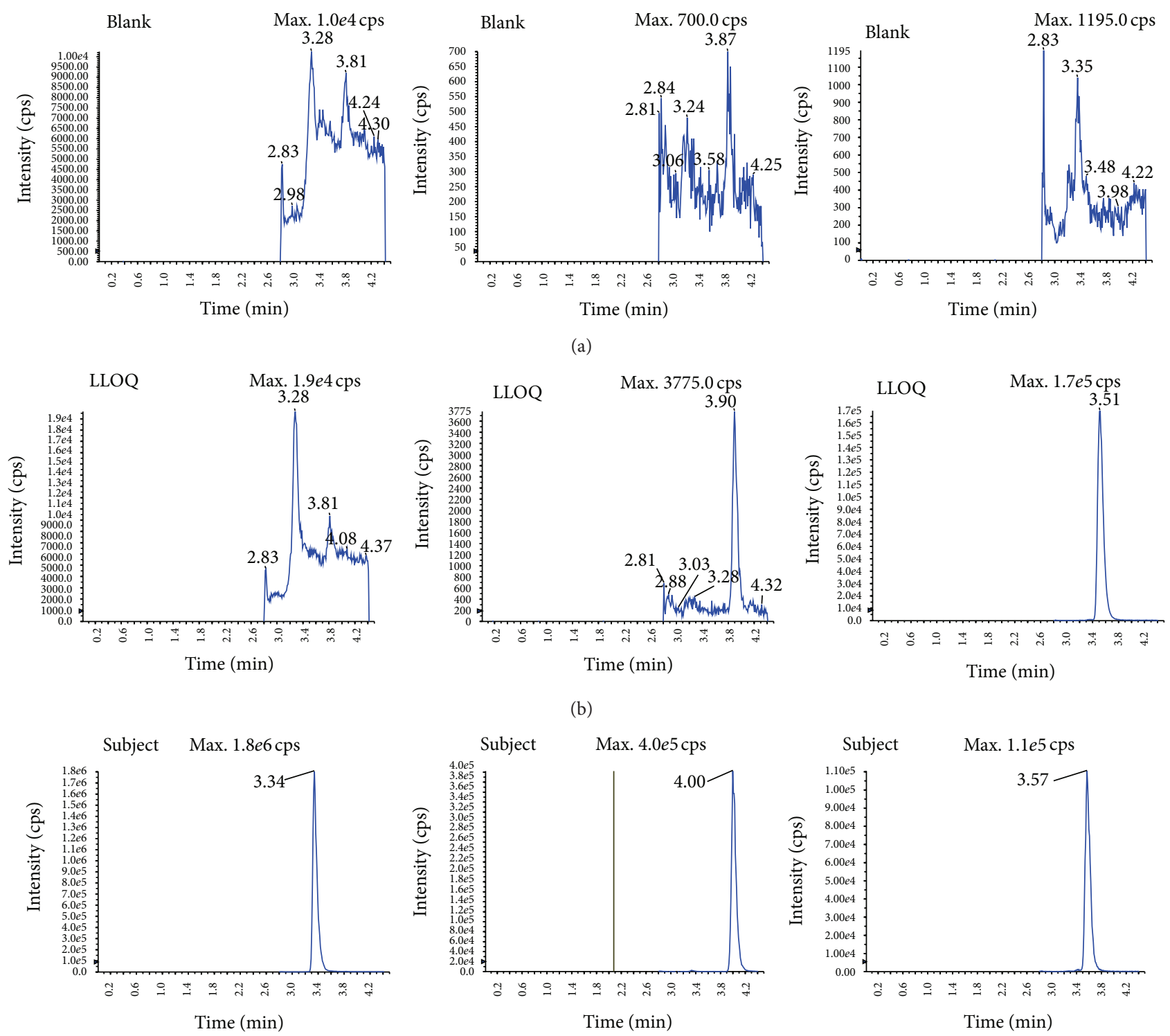

(c)

FIGURE 2: Representative MRM chromatograms for NA (I), NUA (II), and IS 5-FU (III) in human plasma: (a) blank plasma sample; (b) blank plasma sample spiked with NA and NUA at the lowest limit of quantification $(5 \mathrm{ng} / \mathrm{mL})$ and IS (1000 ng/mL); (c) plasma sample obtained from a subject $12 \mathrm{~h}$ after oral administration of 3 tablets of Niacin extended-release/Simvastatin.

with those of spiked samples. No interference was detected from endogenous substances within the analytes and IS (Figure 2).

3.4.2. Linearity of Calibration Curves and Lower Limit of Quantification. The linear ranges were both $5-800 \mathrm{ng} / \mathrm{mL}$ for NA and for NUA in the human plasma with correlation coefficients of $>0.995$. The lower limits of quantification, defined as the lowest concentration measured with $\pm 15 \%$ accuracy and $\leq 15 \%$ precision, were both $5 \mathrm{ng} / \mathrm{mL}$ for NA with relative errors $6.1 \%$ and NUA with relative errors $0.7 \%$.
3.4.3. Precision and Accuracy. Assay precision and accuracy were determined by using QC samples at three concentrations in replicates $(n=6)$ by performing complete analytical runs on the same day and on three consecutive days. The within- and between-run precision and accuracy for the QC samples are summarized in Table 1.

3.4.4. Extraction Recovery. The average extraction recoveries for NA were $89.7 \pm 2.5 \%, 93.3 \pm 6.3 \%$, and $90.4 \pm 5.4 \%$ at the concentrations of 10,60 , and $600 \mathrm{ng} / \mathrm{mL}$, respectively. For NUA, the mean recoveries were $100.7 \pm 7.3 \%, 103.0 \pm 7.1 \%$, and 
TABLE 2: Stability data for stock solutions of NA and NUA $6 \mathrm{~h}$ in room temperature and 7 days at $-20^{\circ} \mathrm{C}$ (before and after).

\begin{tabular}{|c|c|c|c|}
\hline & \multicolumn{3}{|c|}{ Response $\left(\times 10^{5}\right)$} \\
\hline & Before & Six h at room temperature & Seven days at $-20^{\circ} \mathrm{C}$ \\
\hline \multirow{6}{*}{ NA } & 14.7 & 14.6 & 13.9 \\
\hline & 15.5 & 15.6 & 15.4 \\
\hline & 14.2 & 14.1 & 13.9 \\
\hline & 14.0 & 15.8 & 14.2 \\
\hline & 14.7 & 15.1 & 14.3 \\
\hline & 16.9 & 13.8 & 13.1 \\
\hline R.E.\% & & -1.1 & -5.8 \\
\hline \multirow{6}{*}{ NUA } & 6.0 & 6.8 & 6.1 \\
\hline & 6.6 & 6.5 & 6.3 \\
\hline & 6.3 & 6.5 & 6.4 \\
\hline & 6.4 & 6.7 & 6.4 \\
\hline & 6.5 & 6.3 & 6.6 \\
\hline & 7.0 & 6.3 & 6.5 \\
\hline R.E.\% & & 0.8 & -1.6 \\
\hline
\end{tabular}

$98.3 \pm 2.4 \%$ at the concentrations of 10,60 , and $600 \mathrm{ng} / \mathrm{mL}$, respectively. The extraction recovery of the IS was $90.2 \pm 3.7 \%$ (5-FU).

3.4.5. Matrix Effect. Coeluting matrix compounds, in the plasma samples, may reduce or enhance the ion intensity of the analytes and affect the reproducibility and accuracy of the assay. The matrix effect was assessed as follows: to the blank matrix from six different individuals, analytes were added at three concentrations (low, middle, and high), making a total of 18 samples. These samples were subjected to the analytical procedure and compared with the standard working solutions.

The relative matrix effect of NA was $80.0-84.4,83.1-$ 96.5 , and $80.8-91.2 \%$ at the concentrations of 10,60 , and $600 \mathrm{ng} / \mathrm{mL}$, respectively. The relative matrix effect of NUA was $81.7-96.2,85.3-99.3$, and $83.5-96.6 \%$ at the concentrations of 10,60 , and $600 \mathrm{ng} / \mathrm{mL}$, respectively. It indicated that the matrix effects had no practical effect on the quantification of NA and NUA.

3.4.6. Dilution Integrity. The relative errors for QC samples of 20 -fold dilution with control matrix for NA were from $-3.7 \%$ to $1.2 \%$ and $11.7 \%$ to $2.4 \%$ for NUA. The results demonstrated that plasma samples could be diluted 20 -fold with control matrix with no effect on the accurate quantitation of NA and NUA.

3.4.7. Stability. The stability of NA and NUA in human plasma was investigated under a variety of storage and process conditions. The results of the stability studies (Tables 2 and 3) did not reveal any significant degradation under the conditions of the experiment.

3.5. Application of the Method. After validation, the LCMS/MS method was used to determine NA and NUA concentrations in plasma samples after oral administration of
Niacin extended-release/Simvastatin to two groups' healthy volunteers. The results were summarized in Table 4 .

Figure 3 displays the mean plasma concentration-time curve of NA and NUA. It was showed that after single oral dose of 1 tablet Niacin extended-release/Simvastatin, the mean maximum plasma concentration $\left(C_{\max }\right)$ was $159.8 \pm$ 125.3 and $836.0 \pm 398.9 \mathrm{ng} / \mathrm{mL}$, and the time to reach maximum concentration $\left(T_{\max }\right)$ was $2.94 \pm 2.63$ and $2.06 \pm$ $1.60 \mathrm{~h}$ for NA and NUA, respectively. The half-life $\left(t_{1 / 2}\right)$ was found to be $8.80 \pm 8.49$ and $1.70 \pm 0.80 \mathrm{~h}$ for NA and NUA, respectively. The $\mathrm{AUC}_{0-t}$ for NA and NUA was $348.6 \pm 191.7$ and $2152 \pm 1362 \mathrm{ng} \cdot \mathrm{h} / \mathrm{mL}$, respectively. After single oral dose of 2 tablets Niacin extended-release/Simvastatin, $C_{\max }$ was $904.0 \pm 487.0$ and $1628 \pm 636.0 \mathrm{ng} / \mathrm{mL}$, and $T_{\max }$ was $1.82 \pm 1.69$ and $3.03 \pm 2.19 \mathrm{~h}$ for NA and NUA, respectively. The $t_{1 / 2}$ was found to be $7.33 \pm 8.68$ and $2.55 \pm 1.26 \mathrm{~h}$ for NA and NUA, respectively. The $\mathrm{AUC}_{0-t}$ for NA and NUA was $1538 \pm 957.0$ and $5396 \pm 3215 \mathrm{ng} \cdot \mathrm{h} / \mathrm{mL}$, respectively. After single oral dose of 3 tablets Niacin extended-release/Simvastatin, $C_{\max }$ was $2476 \pm 1431$ and $2794 \pm 1038 \mathrm{ng} / \mathrm{mL}$, and $T_{\max }$ was $2.42 \pm 1.64$ and $2.33 \pm 1.05 \mathrm{~h}$ for NA and NUA, respectively. The $t_{1 / 2}$ was found to be $5.40 \pm 4.57$ and $2.72 \pm 1.83 \mathrm{~h}$ for NA and NUA, respectively. The $\mathrm{AUC}_{0-t}$ for NA and NUA was $6021 \pm 6579$ and $10210 \pm 7076 \mathrm{ng} \cdot \mathrm{h} / \mathrm{mL}$, respectively.

We found that there was significant difference between subjects, while there was no significant statistical difference $(P>0.05)$ in the most main pharmacokinetic parameters of NA and NUA between treatments.

\section{Conclusion}

In this study, the LC-MS/MS method were developed and validated for the quantification of NA and its active metabolite NUA in human plasma. The method has been successfully applied to pharmacokinetic study after oral administration of a fixed dose combination tablet of Niacin extended-release/Simvastatin $(500 \mathrm{mg} / 10 \mathrm{mg}$ ) to the humans. 
TABLE 3: Stability data for NA and NUA in human plasma under different storage conditions (before and after analysis, $n=3$ ).

\begin{tabular}{|c|c|c|c|c|}
\hline & Storage conditions & $\begin{array}{l}\text { Added } C \\
(\mathrm{ng} / \mathrm{mL})\end{array}$ & $\begin{array}{c}\text { Before C/R.E. } \\
(\mathrm{ng} / \mathrm{mL}) / \%\end{array}$ & $\begin{array}{c}\text { Found C/R.E. } \\
(\mathrm{ng} / \mathrm{mL}) / \%\end{array}$ \\
\hline \multirow{12}{*}{ NA } & \multirow{3}{*}{$\begin{array}{l}\text { Short-term } \\
\left(3 \mathrm{~h} \text { at } 24^{\circ} \mathrm{C}\right)\end{array}$} & 10.0 & $9.4 /-5.8$ & $9.1 /-8.9$ \\
\hline & & 60.0 & $60.2 / 0.4$ & $58.8 /-2.1$ \\
\hline & & 600.0 & $611.0 / 2.17$ & $636.3 / 6.0$ \\
\hline & \multirow{3}{*}{$\begin{array}{l}\text { Long-term } \\
\left(2 \text { months at }-20^{\circ} \mathrm{C}\right)\end{array}$} & 10.0 & $9.4 /-5.7$ & $9.6 /-4.1$ \\
\hline & & 60.0 & $56.0 /-6.6$ & $53.7 /-10.6$ \\
\hline & & 600.0 & $527.0 /-12.2$ & $595.3 /-0.8$ \\
\hline & \multirow{3}{*}{ Three freeze/thaw cycles } & 10.0 & $9.4 /-1.9$ & $9.5 /-4.6$ \\
\hline & & 60.0 & $60.2 / 0.4$ & $58.0 /-3.28$ \\
\hline & & 600.0 & $611.0 / 1.8$ & $546.3 /-9.0$ \\
\hline & \multirow{3}{*}{ Autosampler for $4 \mathrm{~h}\left(24^{\circ} \mathrm{C}\right)$} & 10.0 & $9.9 /-1.0$ & $9.6 /-3.7$ \\
\hline & & 60.0 & $61.6 / 2.6$ & $62.7 / 4.5$ \\
\hline & & 600.0 & $597.4 / 0.4$ & $578.3 /-3.6$ \\
\hline \multirow{12}{*}{ NUA } & \multirow{3}{*}{$\begin{array}{l}\text { Short-term } \\
\left(3 \mathrm{~h} \text { at } 24^{\circ} \mathrm{C}\right)\end{array}$} & 10.0 & $10.8 / 7.7$ & $11.0 / 9.7$ \\
\hline & & 60.0 & $60.1 / 0.2$ & $63.6 / 5.9$ \\
\hline & & 600.0 & $624.7 / 4.1$ & $628.7 / 4.8$ \\
\hline & \multirow{3}{*}{$\begin{array}{l}\text { Long-term } \\
\left(2 \text { months at }-20^{\circ} \mathrm{C}\right)\end{array}$} & 10.0 & $10.2 / 2.3$ & $10.6 / 6.4$ \\
\hline & & 60.0 & $60.5 / 0.8$ & $59.1 /-1.5$ \\
\hline & & 600.0 & $608.0 / 1.3$ & $579.3 /-3.4$ \\
\hline & \multirow{3}{*}{ Three freeze/thaw cycles } & 10.0 & $10.8 / 7.7$ & $10.8 / 8.3$ \\
\hline & & 60.0 & $60.1 / 0.2$ & $63.3 / 5.6$ \\
\hline & & 600.0 & $624.7 / 4.1$ & $618.3 / 3.1$ \\
\hline & \multirow{3}{*}{ Autosampler for $4 \mathrm{~h}\left(24^{\circ} \mathrm{C}\right)$} & 10.0 & $10.9 / 9.3$ & $10.7 / 7.3$ \\
\hline & & 60.0 & $59.4 /-0.9$ & $67.0 / 11.7$ \\
\hline & & 600.0 & $611.3 / 1.9$ & $598.3 /-0.3$ \\
\hline
\end{tabular}

TABLE 4: The main pharmacokinetic parameters for NA and NUA after single oral doses of Niacin extended-release/Simvastatin to healthy volunteers (mean \pm S.D., $n=12$ ).

\begin{tabular}{|c|c|c|c|c|c|c|}
\hline & \multicolumn{2}{|c|}{1 tablet } & \multicolumn{2}{|c|}{2 tablets } & \multicolumn{2}{|c|}{3 tablets } \\
\hline & $\mathrm{NA}$ & NUA & NA & NUA & NA & NUA \\
\hline $\mathrm{AUC}_{0-t}(\mu \mathrm{g} \cdot \mathrm{h} / \mathrm{mL})$ & $0.3846 \pm 0.1917$ & $2.151 \pm 1.362$ & $1.538 \pm 0.9570$ & $5.396 \pm 3.215$ & $6.021 \pm 6.579$ & $10.21 \pm 7.076$ \\
\hline $\mathrm{AUC}_{0-\infty}(\mu \mathrm{g} \cdot \mathrm{h} / \mathrm{mL})$ & $0.5176 \pm 0.2265$ & $2.181 \pm 1.368$ & $1.719 \pm 0.9230$ & $5.478 \pm 3.249$ & $6.097 \pm 6.555$ & $10.25 \pm 7.091$ \\
\hline$t_{1 / 2}(\mathrm{~h})$ & $8.80 \pm 8.49$ & $1.70 \pm 0.801$ & $7.33 \pm 8.68$ & $2.55 \pm 1.26$ & $5.40 \pm 4.57$ & $2.72 \pm 1.83$ \\
\hline$K_{e}(1 / \mathrm{h})$ & $0.19 \pm 0.20$ & $0.53 \pm 0.31$ & $0.43 \pm 0.69$ & $0.33 \pm 0.14$ & $0.27 \pm 0.25$ & $0.33 \pm 0.15$ \\
\hline $\mathrm{MRT}_{0-t}(\mathrm{~h})$ & $5.37 \pm 1.96$ & $2.91 \pm 0.74$ & $4.40 \pm 2.21$ & $3.60 \pm 1.32$ & $3.65 \pm 1.33$ & $3.79 \pm 1.11$ \\
\hline$C_{\max }(\mu \mathrm{g} / \mathrm{mL})$ & $0.1598 \pm 0.1253$ & $0.8360 \pm 0.3989$ & $0.9040 \pm 0.4870$ & $1.628 \pm 0.6360$ & $2.476 \pm 1.431$ & $2.794 \pm 1.038$ \\
\hline$T_{\max }(\mathrm{h})$ & $2.94 \pm 2.63$ & $2.06 \pm 1.60$ & $1.82 \pm 1.69$ & $3.03 \pm 2.19$ & $2.42 \pm 1.64$ & $2.33 \pm 1.05$ \\
\hline $\mathrm{CL}_{z} / F(\mathrm{~L} / \mathrm{h})$ & $1271 \pm 850.0$ & $287.8 \pm 128.2$ & $744.0 \pm 356.0$ & $224.8 \pm 91.90$ & $526.0 \pm 421.0$ & $189.3 \pm 94.20$ \\
\hline$V_{z} / F\left(\times 10^{3} \mathrm{~L}\right)$ & $13.71 \pm 11.60$ & $0.6490 \pm 0.3380$ & $7.649 \pm 9.324$ & $0.8210 \pm 0.5230$ & $5.199 \pm 6.651$ & $0.6960 \pm 0.4580$ \\
\hline
\end{tabular}

The results showed that the plasma concentration and pharmacokinetic performance of NA and NUA have significant difference between individuals. It indicated that much attention should be paid during the clinical use especially in coadministration when suffering from several illnesses. Our results have clinical implications and warrant further investigation of Niacin extended-release/ Simvastatin.

\section{Conflict of Interests}

The authors declare that they have no conflict of interests.

\section{Acknowledgment}

This study was supported by the Key Project of the National 12th Five-Year Research Program of China (no. 2012ZX09303016-002). 

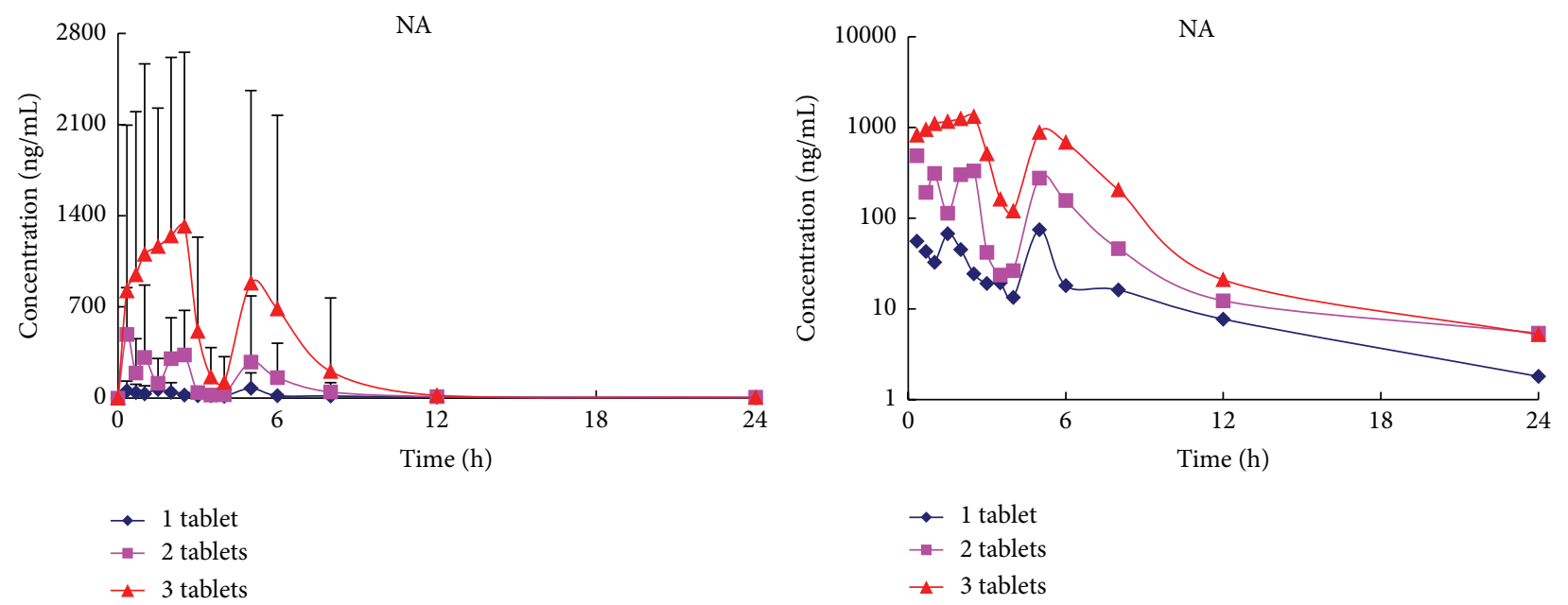

(a)
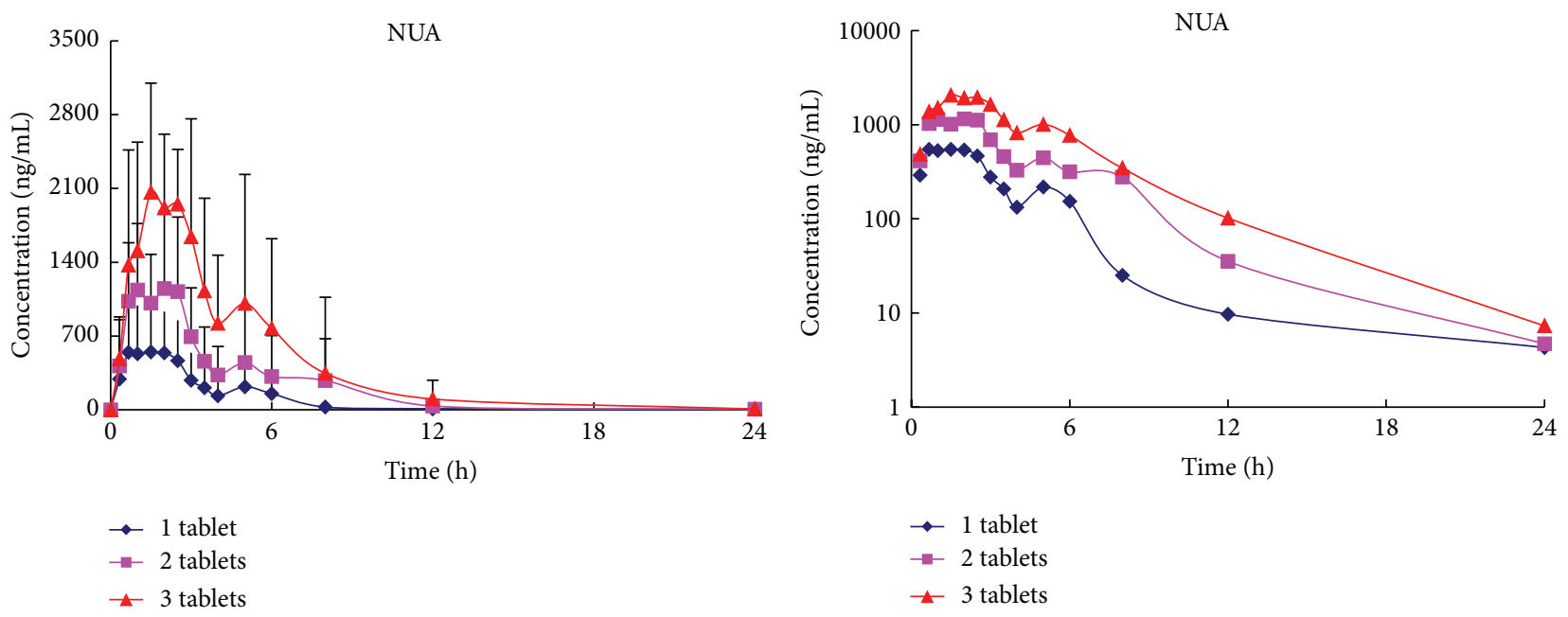

(b)

Figure 3: Mean plasma concentration-time profiles and logarithmic transformation profiles of NA (a) and NUA (b) after oral single dose administration of Niacin extended-release/Simvastatin (1 tablet $500 \mathrm{mg} / 10 \mathrm{mg}, 2$ tablets $1000 \mathrm{mg} / 20 \mathrm{mg}$, and 3 tablets $1500 \mathrm{mg} / 30 \mathrm{mg}$ ) to volunteers $(n=12)$.

\section{References}

[1] P. P. Toth, K. M. Thakker, P. Jiang, and R. J. Padley, "Niacin extended-release/simvastatin combination therapy produces larger favorable changes in high-density lipoprotein particles than atorvastatin monotherapy," Vascular Health and Risk Management, vol. 8, no. 1, pp. 39-44, 2012.

[2] P. Pfuhl, U. Kärcher, N. Häring, A. Baumeister, M. A. Tawab, and M. Schubert-Zsilavecz, "Simultaneous determination of niacin, niacinamide and nicotinuric acid in human plasma," Journal of Pharmaceutical and Biomedical Analysis, vol. 36, no. 5, pp. 10451052, 2005.

[3] M. Szafarz, M. Lomnicka, M. Sternak, S. Chlopicki, and J. Szymura-Oleksiak, "Simultaneous determination of nicotinic acid and its four metabolites in rat plasma using high performance liquid chromatography with tandem mass spectrometric detection (LC/MS/MS)," Journal of Chromatography B, vol. 878, no. 11-12, pp. 895-902, 2010.
[4] P. K. Tiwari and P. Sathe, "Development and validation of HPTLC method for niacin and simvastatin in binary combination," Advances in Bioscience and Biotechnology, vol. 1, pp. 131135, 2010.

[5] Y.-Y. Jia, S. Ying, C.-T. Lu et al., "Pharmacokinetics of singledose and multi-dose of lovastatin/niacin ER tablet in healthy volunteers," Chromatography Research International, vol. 2012, Article ID 437075, 11 pages, 2012.

[6] M. Kazemipour, M. Ansari, H. Ramezani, and M. Moradalizadeh, "Simultaneous determination of lovastatin and niacin in tablet by first and third derivative spectrophotometry and $\mathrm{H}$ point standard addition methods," Research in Pharmaceutical Sciences, vol. 7, no. 2, pp. 95-102, 2012.

[7] X.-Q. Zhao, J. S. Morse, A. A. Dowdy et al., "Safety and tolerability of Simvastatin plus niacin in patients with coronary artery disease and low high-density lipoprotein cholesterol (The HDL Atherosclerosis Treatment Study)," The American Journal of Cardiology, vol. 93, no. 3, pp. 307-312, 2004. 
[8] A. L.-W. Katherine, "Niacin extended release (ER)/simvastatin (Simcor)," Drug and Profile Report, vol. 10, no. 4, pp. 253-260, 2010.

[9] "Estimation of Simvastatin and nicotinic acid by high performance thin layer chromatography in pharmaceutical dosage form," Universal Journal of Pharmacy, vol. 2, no. 2, pp. 91-94, 2013.

[10] J. K. Inamadugu, R. Damaramadugu, R. Mullangi, and V. Ponneri, "Simultaneous determination of niacin and its metabolites-nicotinamide, nicotinuric acid and $\mathrm{N}$-methyl2-pyridone-5-carboxamide-in human plasma by LC-MS/MS and its application to a human pharmacokinetic study," Biomedical Chromatography, vol. 24, no. 10, pp. 1059-1074, 2010.

[11] J. N. Sangshetti, Z. Zaheer, M. Aqeel, and M. H. G. Dehghan, "Validated spectrophotometric method for simultaneous estimation of atorvastatin and nicotinic acid in combined pharmaceutical dosage form," International Journal of PharmTech Research, vol. 4, no. 3, pp. 999-1003, 2012.

[12] M. Liu, D. Zhang, X. Wang et al., "Simultaneous quantification of niacin and its three main metabolites in human plasma by LC-MS/MS," Journal of Chromatography B, vol. 904, pp. 107-114, 2012.

[13] L. Wang, Y.-P. Qin, X.-L. Gong et al., "Determination of nicacid and its metabolites in human plasma by HPLC-MS/MS," Journal of Sichuan University (Medical Science Edition), vol. 41, no. 6, pp. 1051-1054, 2010.

[14] M. Liu, X. L. Wang, D. Zhang et al., "Pharmacokinetics of niacin, simvastatin and their metabolites in healthy Chinese subjects after single and multiple doses of a fixed dose combination tablet of niacin extended release/simvastatin," Drug Research, vol. 64, no. 6, pp. 296-300, 2014.

[15] Y. Hsieh and J. Chen, "Simultaneous determination of nicotinic acid and its metabolites using hydrophilic interaction chromatography with tandem mass spectrometry," Rapid Communications in Mass Spectrometry, vol. 19, no. 21, pp. 3031-3036, 2005.

[16] N. R. Pilli, R. Mullangi, J. K. Inamadugu, I. K. Nallapati, and S. Rao, "Simultaneous determination of simvastatin, lovastatin and niacin in human plasma by LC-MS/MS and its application to a human pharmacokinetic study," Biomedical Chromatography, vol. 26, no. 4, pp. 476-484, 2012.

[17] V. B. Ravi, R. Mullangi, J. K. Inamadugu, N. R. Pilli, R. Gajula, and V. Ponneri, "Simultaneous determination of atorvastatin and niacin in human plasma by LC-MS/MS and its application to a human pharmacokinetic study," Biomedical Chromatography, vol. 26, no. 11, pp. 1436-1443, 2012.

[18] 2001, http://www.fda.gov/Drugs/GuidanceComplianceRegulatoryInformation/Guidances/default.htm.

[19] http://www.sda.gov.cn/gsz05106/08.pdf.

[20] B. K. Matuszewski, M. L. Constanzer, and C. M. Chavez-Eng, "Strategies for the assessment of matrix effect in quantitative bioanalytical methods based on HPLC-MS/MS," Analytical Chemistry, vol. 75, no. 13, pp. 3019-3030, 2003.

[21] https://en.wikipedia.org/wiki/Declaration_of_Helsinki. 

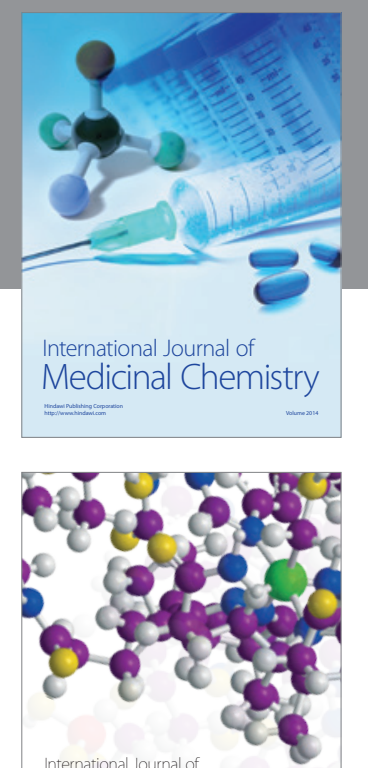

\section{Carbohydrate} Chemistry

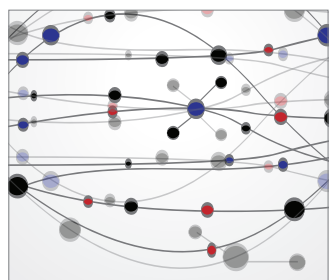

The Scientific World Journal
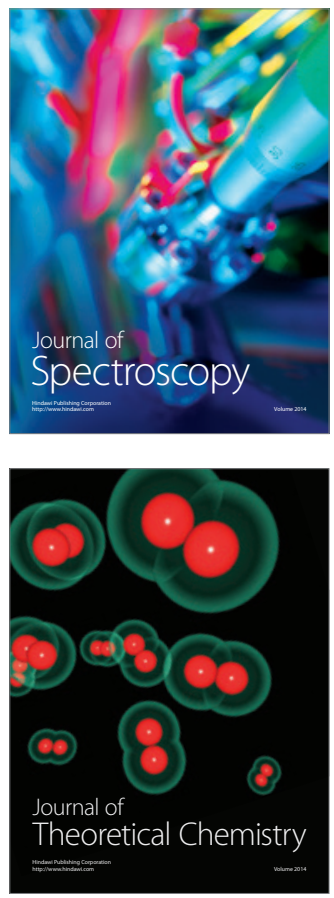
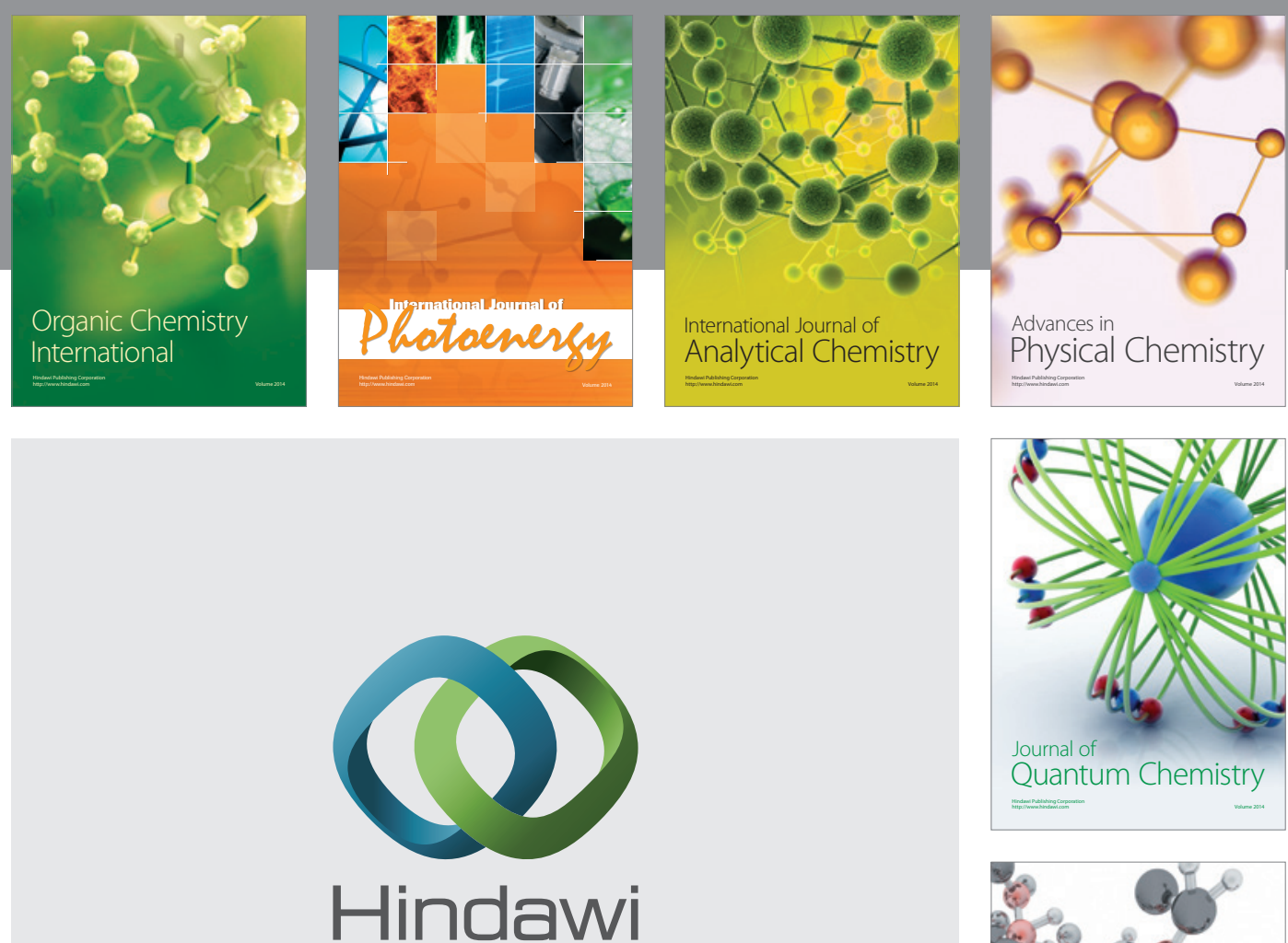

Submit your manuscripts at

http://www.hindawi.com

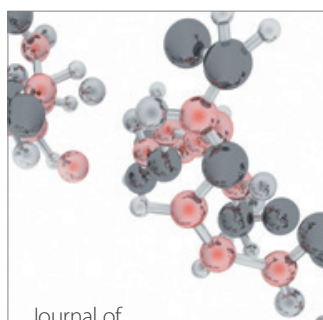

Analytical Methods

in Chemistry

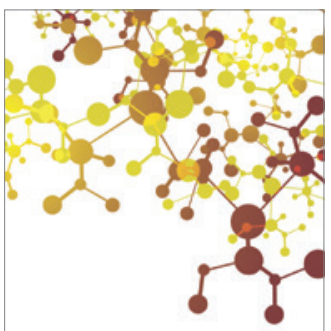

Journal of

Applied Chemistry

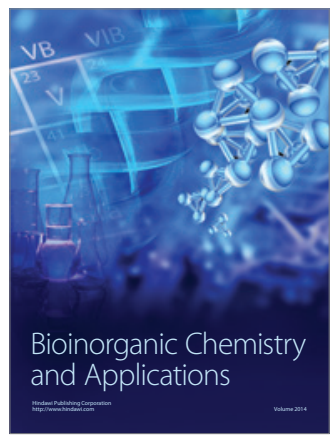

Inorganic Chemistry
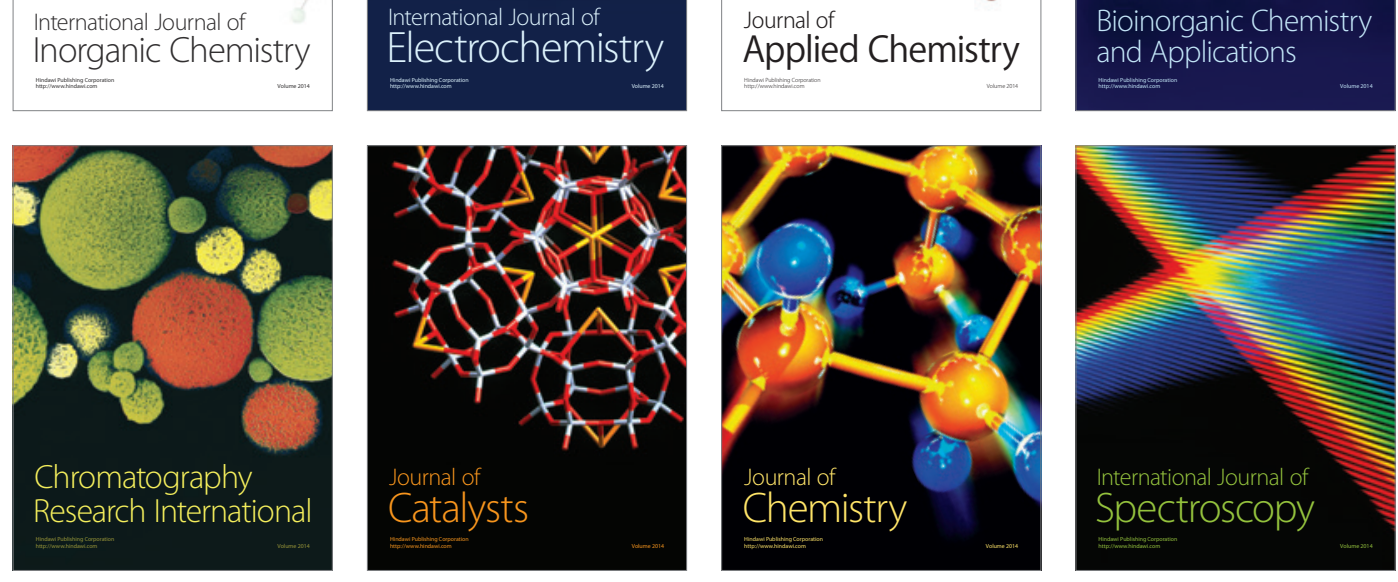